\title{
Evaluation and Prediction of Status of Coastal Ecosystem
}

\author{
Xuncheng Fan ${ }^{1}$, Lili Zhao ${ }^{1}$, Dongjin $\mathrm{He}^{2 *}$ \\ ${ }^{1}$ College of Urban and Rural Construction, Shaoyang University, Shaoyang, 422000 China \\ ${ }^{2}$ Forestry College, Fujian Agriculture and Forestry University, Fuzhou, 350002 China
}

Received: 23 February 2021

Accepted: 27 April 2021

\begin{abstract}
Coastal zones are located at the intersection of the two major ecosystems of ocean and land. Three-fifths of the global population lives in coastal zones, which provide ecological services and are the most economically developed areas. However, the coastal ecosystem is seriously threatened because of long-term human disturbances. In this study, the Ningde coastal zone was selected as the study area. The Pressure-State-Response model and Analytic Hierarchy Process were used to evaluate the ecosystem of the Ningde coastal zone in 2000, 2009, and 2014. The Markov model was used to predict the status of the Ningde coastal zone ecosystem in 2024. Finally, several problems, corresponding countermeasures, and suggestions in the management of the Ningde coastal ecosystem were proposed. The ecosystem status in the coastal zone of Ningde improved continuously from 2000 to 2009. Although the status of the ecosystem declined slightly from 2009 to 2014, it currently remains fair. The status of the Ningde coastal ecosystem will be worse in 2024 than that in 2014, indicating that an increase in the area of forest and grassland and a decrease in the area of dry land and paddy field is not effective. The main problems affecting the coastal ecosystem of Ningde were that the area of aquaculture was blindly expanded and the role of water bodies in protecting the environment was ignored. The forest ecosystem in the coastal zone of Ningde was vulnerable to external disturbance owing to the single species of forest trees and the lack of a large area of land suitable for forests.
\end{abstract}

Keywords: PSR model, AHP, Markov model, Ningde, land use

\section{Introduction}

The global population has increased significantly since the last century. In 1750 , the total population of the world was approximately 717 million. In 1900, it was over 1.5 billion. In 2000, it reached 6 billion,

*e-mail: 1525972790@qq.com

and by 2030, it is expected to reach 8.5 billion [1-2]. The significant increase in population is a major source of environmental problems worldwide [2]. Ecosystems suffer from human activities such as air pollution, soil erosion, and ecosystem degradation with the continuous anthropogenic development, restricting regional economic development [3]. Therefore, a healthy ecosystem is central to sustainable development [4-6]. The sustainable development of ecosystems assists current and future generations to obtain living resources 
from ecosystems on a continuous basis [7]. At present, keeping ecosystems healthy has become a widespread issue of social concern.

The concept of a healthy ecosystem was first defined by Rapport et al. [3]. It usually refers to a certain type of ecosystem that can maintain a good organizational structure for a long time, meet human material life and ecological needs, and recover from stress. The integrity, stability, and sustainability of a healthy ecosystem are considered the ultimate environmental management goals [8]. Therefore, evaluating and predicting the status of the ecosystem can effectively identify the crisis of the ecosystem, which is greatly significant to sustainable development.

Coastal zones are transition zones between the ocean and the land. They have become some of the most concentrated areas in the world owing to the rich natural resources and superior geographic location [9]. In recent years, the economic development of coastal areas resulted in structural damage and reduced the functions of coastal ecosystems [10]. In addition, the degradation of coastal ecosystems has led to the endangerment and extinction of some species in coastal zones [11]. Therefore, it is particularly important to evaluate and predict the status of coastal ecosystems that will help us achieve coordinated development of the society and economy of coastal areas and maintain the stability of coastal ecosystems.

The coastal zone of Ningde is the most economically developed and dynamic frontier zone of Ningde City. The gross domestic product of this zone soared from 14.27 billion yuan in 2000 to 192.10 billion yuan in 2019, increasing nearly 14 times [12-14]. The population of the zone has proliferated from 1.93 million to 2.04 million. By the end of 2019, the permanent population in the coastal zone accounted for $70 \%$ of the total population in Ningde City. The population density has also increased by 33 persons $/ \mathrm{km}^{2}$ in 14 years. The rapid population growth is susceptible to destroying the ecosystem in the zone.

The coastal zone of Ningde City was selected as the study region in this work. The Pressure-State-Response (PSR) model was used to construct an indicator system for ecosystem evaluation, and the Analytic Hierarchy Process (AHP) was used to determine the weights of different indicators. Remote sensing and a geographic information system were used to obtain the values of the evaluation indicators, which were then applied to the ecosystem evaluation. Finally, the Markov model was used to predict the ecosystem status of the Ningde coastal zone, and some countermeasures and suggestions were put forward. This study aimed to provide beneficial support to the restoration of this ecosystem and the rational development of the resources in the Ningde coastal zone. Also, this study provides a reference for ecosystem protection in other coastal areas.

\section{Materials and Methods}

\section{Overview of the Research Area}

The Ningde Coastal Zone is a part of the Fujian province, which is located on the southeastern coast of China. It consists of four cities, viz. Jiaocheng, Fu'an, Fuding, and Xiapu (Fig. 1). Furthermore, this zone is located in the middle of the three major economic zones of the Yangtze River Delta, the Pearl River Delta, and Taiwan in China, it covers $6,253 \mathrm{~km}^{2}$, and it has a mid-subtropical maritime monsoon climate. In

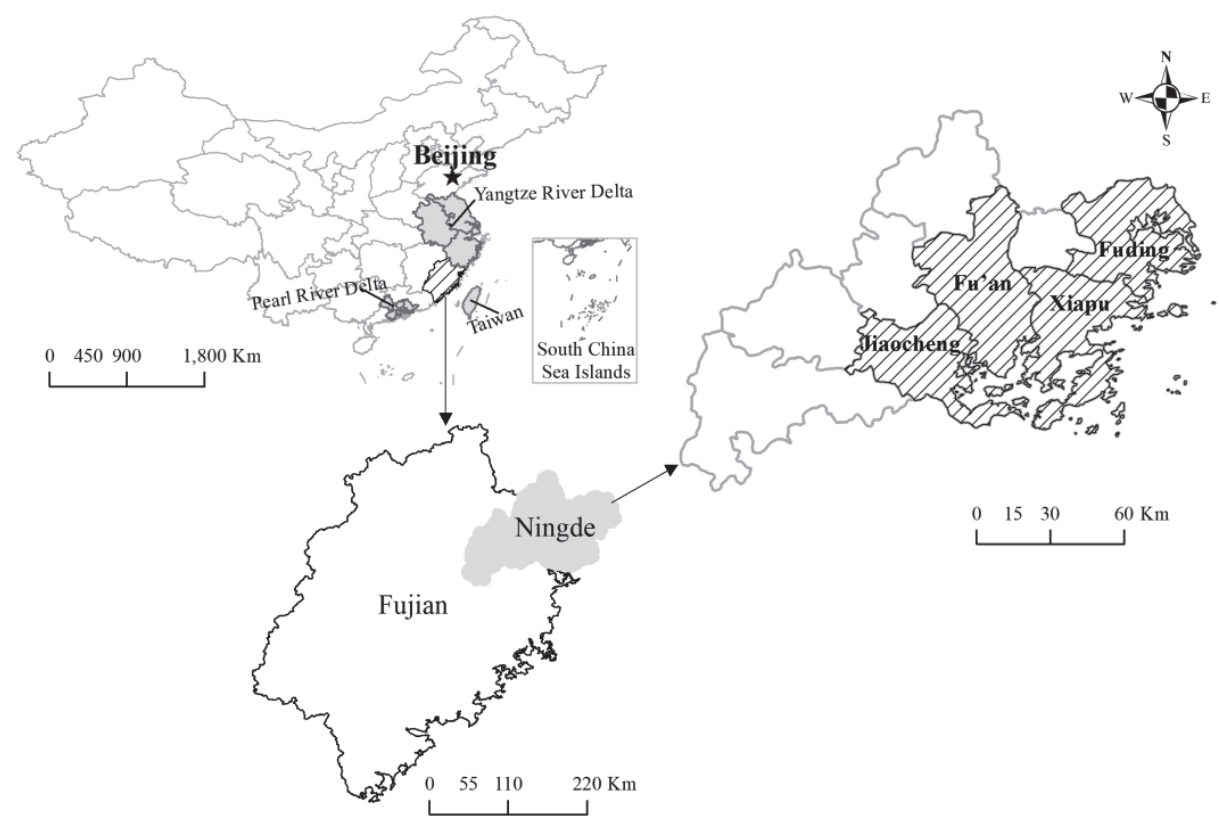

Fig. 1. Map of study area. 
2019, the annual average temperature was between $16.00^{\circ} \mathrm{C}$ and $20.70^{\circ} \mathrm{C}$, the annual rainfall was between $1193.70 \mathrm{~mm}$ and $2018.80 \mathrm{~mm}$, and the annual sunshine hours were between $1401.60 \mathrm{~h}$ and $1707.20 \mathrm{~h}$ [14]. It is dominated by mountains and hills, accounting for $73.3 \%$ of the total land area. The mainland coastline is $878.16 \mathrm{~km}$ long, accounting for one-third of the Fujian province. The sea area is $44,500 \mathrm{~km}^{2}$, accounting for one-third of that of the province [14]. The Ningde coastal zone is rich in aquatic resources, with more than 600 types of aquatic fauna. It includes more than 500 varieties of fish, 60 species of shrimps and crabs, 70 species of shellfish, and more than ten species of algae. It is rich in large yellow croaker, prawns, grouper, erdu cockles, and sword clams. The artificial propagation and nursery technology of large yellow croaker in this area has reached the leading international level.

\section{Data Sources and Data Processing}

The images of Landsat-5 TM (2000 and 2009) and Landsat- 8 OLI (2014) of the Ningde coastal zone were used as the basic data. These remote sensing data were downloaded from the Geospatial Data Cloud (http:// www.gscloud.cn/). The steps for processing these data were as follows.

First, ENVI 5.1, was used to process the remote sensing images based on a 1:50,000 topographic map. Second, interpretation signs of the coastal land-use types were established depending on the color tone, shape, texture, and field survey. According to "Classification of Land Use Status" (GB/T21020-2017) and the geographic characteristics of the Ningde coastal zone, the land-use types were divided into forest and grassland, rivers, lakes, construction land, reservoirs, aquaculture, dry land, paddy field, and other land using object-oriented classification methods. Third, the accuracy tests of the classification results in 2000, 2009, and 2014 were carried out. The overall accuracy was $89.3 \%, 94.5 \%$, and $92.5 \%$, and the Kappa coefficients were 0.82 , 0.87 , and 0.84 , respectively. These values were higher than 0.80 (the minimum allowable accuracy); thus, the classification results met the accuracy requirements of land-use change monitoring and could be used to express the land-use status of the study area. Fourth, the small maps generated after classification were merged into adjacent large spots using the clustering statistics and removal analysis of ENVI. Finally, the area and transfer matrix of each land use type were obtained using ENVI.

\section{Ecosystem Status Evaluation}

\section{PSR Model}

The PSR model was initially developed by Rapport [15] and is one of the most widely used models in ecosystem evaluation. The specific index framework is depicted in Fig. 2. The model includes natural environmental factors and human influence factors. In this model, the multivariate methods were used to determine evaluation indicators. Therefore, the status of the ecosystem was evaluated scientifically, comprehensively, and meticulously.

The model is divided into three types of indicators: pressure indicators $(\mathrm{P})$, state indicators $(\mathrm{S})$, and response indicators (R). These include the current

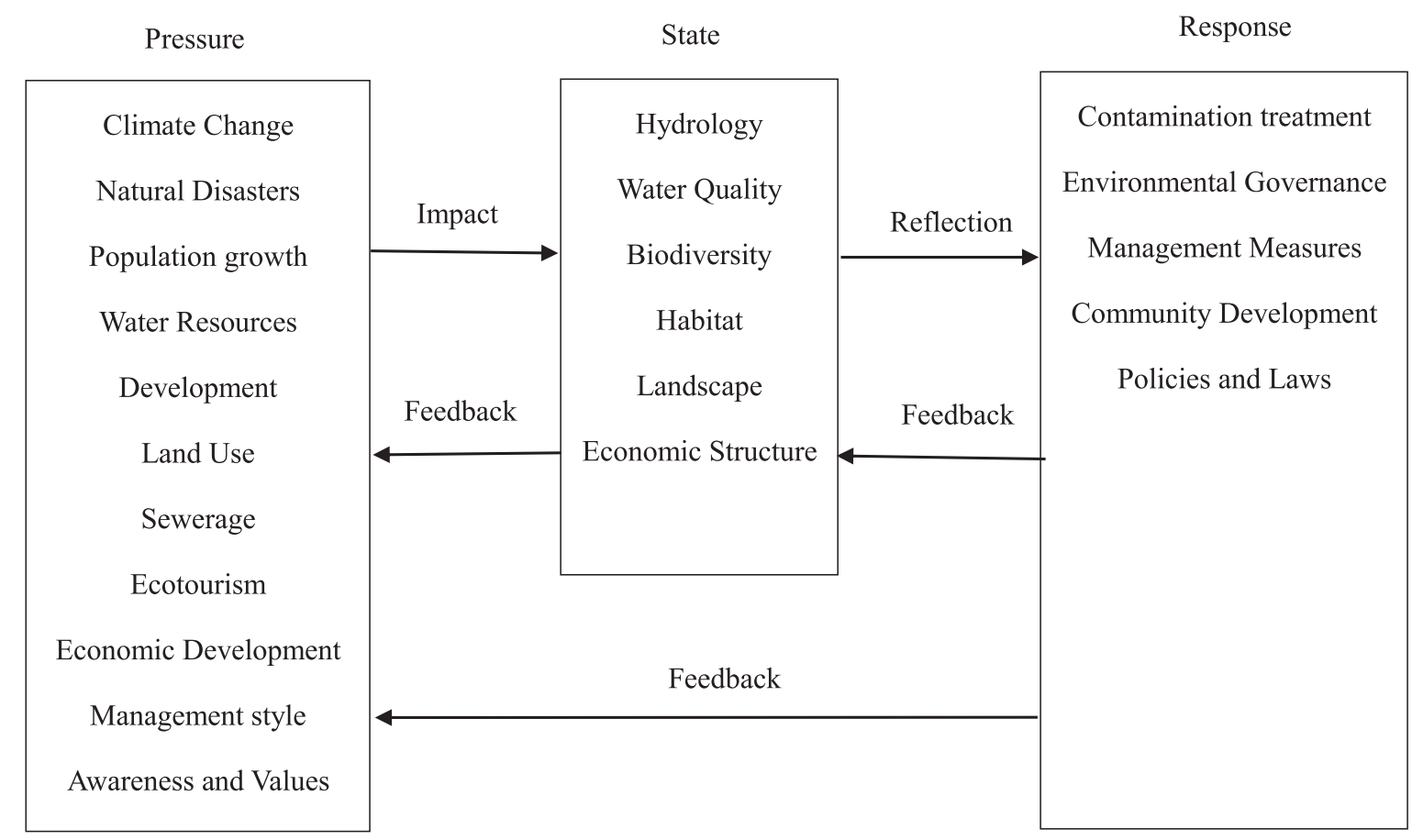

Fig. 2. Framework of PSR model. 
state of the ecosystem and the natural environment, economic structure, etc., which can be regarded as the endogenous factors of ecosystem change. The other indicators are characterized by the regulation measures taken by humans for the sustainable development of the ecosystem after a change in the ecosystem state, regarded as response indicators.

In this study, a model was constructed to evaluate the Ningde coastal ecosystem based on the PSR model, AHP, and the Ningde coastal zone. The model includes three levels: the target, guideline, and indicator levels (Table 1).

The description of each indicator factor is as follows.

Population density $\left(P D, I_{1}\right)$. The specific calculation formula of $P D$ is as follows:

$$
P D=S / A
$$

...where $P D$ represents population density. A greater $\mathrm{PD}$ value represents greater pressure on the ecosystem caused by the population. S represents the number of people, and it was collected from the Ningde Statistical Yearbook; A represents the total area of the study area, and it was obtained from the remote sensing images.

Human disturbance $\left(I, I_{2}\right)$. The specific calculation formula of $I$ is as follows.

$$
I=C N A / A
$$

...where $I$ represents human interference, and it refers to the ratio of the construction land area to the total land area in the study area [16]. A greater value of human disturbance indicates greater pressure on the ecosystem from the construction land used by humans. CNA represents the area of the construction land; $A$ represents the total study area. The values of CNA and A were extracted from the remote sensing images.

Land reclamation rate (LRR, $\left.I_{3}\right)$. The specific calculation formula of LRR is as follows:

$$
L R R=C N A / A
$$

...where $L R R$ is the land reclamation rate, which reflects the ability of the land to continuously provide resources required for human survival [17]. A greater value indicates greater pressure on the ecosystem caused by less available land. $C D A$ is the cultivated land area; $A$ is the total study area. CDA in this study is the sum of dry land and paddy field, which were obtained from the remote sensing images.

Normalized vegetation index (NDVI, $I_{4}$ ). Studies have revealed that NDVI demonstrates a significant positive correlation with the production of vegetation [18-19]. Therefore, NDVI can be used to indicate the vitality of an ecosystem. The calculation formula for the NDVI is as follows:

$$
N D V I=\frac{N I R-R}{N I R+R}
$$

...where $N I R$ is the reflection value in the near-infrared band, and $R$ is the reflection value in the red light band. The value of NDVI is between -1 and 1 . The negative value indicates that the ground is covered by clouds, water, snow, etc., which is highly reflective to visible light; 0 indicates that there is rock or bare soil, etc., and NIR and $R$ are approximately equal; a positive value indicates that there is vegetation coverage. The value of $N D V I$ rises with the increase in vegetation coverage.

Shannon Diversity Index $\left(S H D I, I_{5}\right)$. SHDI reflects the complexity of ecosystem structure. It is one of the representative indexes of landscape heterogeneity [20], and its formula is as follows:

$$
S H D I=-\sum_{i=1}^{m}\left[P_{i} \ln P_{i}\right]
$$

...where $P_{i}$ is the existence probability of patch type $i$ in a landscape, and $\mathrm{m}$ is the total number of patch types.

\begin{tabular}{|c|c|c|}
\hline Target level & Guideline level $A$ & Indicator level $I$ \\
\hline \multirow{9}{*}{$\begin{array}{l}\text { Comprehensive index of } \\
\text { ecosystem evaluation }\end{array}$} & \multirow{3}{*}{ Pressure $A_{1}$} & Population density (people $/ \mathrm{km}^{2}$ ) $\mathrm{I}_{1}$ \\
\hline & & Human disturbance (\%) $\mathrm{I}_{2}$ \\
\hline & & Land reclamation rate $(\%) \mathrm{I}_{3}$ \\
\hline & \multirow{5}{*}{ State $\mathrm{A}_{2}$} & Normalized vegetation index $\mathrm{I}_{4}$ \\
\hline & & Shannon Diversity Index $\mathrm{I}_{5}$ \\
\hline & & Evenness index $\mathrm{I}_{6}$ \\
\hline & & Average patch area $\left(\mathrm{km}^{2}\right) \mathrm{I}_{7}$ \\
\hline & & Resilience indicator $\mathrm{I}_{8}$ \\
\hline & Response $\mathrm{A}_{3}$ & Ecosystem services value $\left(\times 10^{6}\right.$ yuan $) \mathrm{I}_{9}$ \\
\hline
\end{tabular}
When the value of SHDI is 0 , there is only one kind of patch in a landscape. When the value becomes greater, the number of patch types shows an increasing trend, or

Table 1. A model for evaluating the status of Ningde coastal zone ecosystem. 
Table 2. Resilience coefficient of the land use types in Ningde coastal zone.

\begin{tabular}{|c|c|c|}
\hline Landscape types & Coefficients & Description \\
\hline Rivers, lakes, and reservoirs & 1 & \multirow{2}{*}{$\begin{array}{l}\text { Extremely important landscape types, which play a significant role in maintain- } \\
\text { ing the stability and resilience of the ecosystem. }\end{array}$} \\
\hline Forestland and grassland & 0.8 & \\
\hline Aquaculture & 0.6 & \multirow{3}{*}{$\begin{array}{l}\text { Play an important role in maintaining the resilience of the ecosystem and can } \\
\text { provide important material and activity sites for humans. The resilience of the } \\
\text { ecosystem would decline if these landscape types cannot be properly protected } \\
\text { and utilized. }\end{array}$} \\
\hline Dry land and paddy field & 0.5 & \\
\hline Construction land & 0.3 & \\
\hline Other land & 0.1 & Contributes relatively little to the resilience of the ecosystem. \\
\hline
\end{tabular}

the various patch types show an even distribution in a landscape.

Evenness index $\left(E, I_{6}\right) . E$ represents the degree of even distribution of patches in a landscape. It has a negative correlation with dominance [21], and its formula is as follows:

$$
E=\frac{S H D I}{S H D I_{\max }}
$$

...where SHDI $_{\max }$ is the maximum value of the Shannon diversity index. SHDI was obtained by importing the classification maps into the Fragstats software.

Average patch area $\left(A P A, I_{7}\right)$. APA refers to the average area of all patches or a certain type of patch in a study area. A greater value indicates lower fragmentation of the landscape [22]. Its formula is as follows:

$$
A P A=\frac{A}{N P}
$$

...where the unit of $A P A$ is $\mathrm{km}^{2}, A$ represents the total land area of the study area, and $N P$ represents the number of patches. This index was also obtained by importing the classification maps into Fragstats software.

Resilience indicator $\left(\mathrm{F}, I_{8}\right)$. F reflects the ability of an ecosystem affected by pressure to maintain or restore the stability of its structure and function. This indicator is one of the most important indicators that can suggest the state of the ecosystem [23]. Its specific calculation formula is as follows:.

$$
F=\sum_{i} \frac{A_{i} \times F_{i}}{A}
$$

...where $F$ is the resilience of the ecosystem, $A_{i}$ is the area of land use type $I, F_{i}$ is the resilience coefficient of land use type $I$, and $A$ is the total study area. The resilience coefficients of each land-use type in this study were obtained from previous studies [23] (Table 2).

Ecosystem services value $\left(\mathrm{V}, I_{9}\right)$. Ecosystem services refer to the material and living environment provided by ecosystems to human society. The pressure on the ecosystem will affect its ability to provide ecosystem services to human society [24]. Therefore, ecosystem services value was selected as the response indicator of ecosystem evaluation. The formula for calculating the value of ecosystem services is as follows:

$$
V=\sum_{i} A_{i} \times V_{i}
$$

...where $V$ is the ecosystem services value, $A_{i}$ is the area of the land use type $I$, and $\mathrm{V}_{i}$ is the ecosystem service value per unit area of land use type $i$. The ecosystem service value per unit area of each land-use type in the Ningde coastal zone was obtained from previous studies [25-26] (Table 3). Then, the ecosystem services value of the Ningde coastal zone was calculated using the area of each land-use type.

\section{Indicator Weight of Ecosystem Evaluation}

The above indicators were assigned to reasonable weights owing to the different influences of these indicators on the ecosystem. This is of great significance for improving the accuracy of the evaluation. The AHP was used to determine the weights of these indicators.

The AHP, which is a multi-level weight analysis method, was proposed by the American operations researcher Satty [27] in the late 1970s. It integrates people's subjective judgments and objective data,

Table 3. Ecosystem service value per unit area of each land-use type in Ningde coastal zone.

\begin{tabular}{|c|c|}
\hline Landscape types & $\begin{array}{c}\text { Value per unit area } \\
\left(10^{6} \mathrm{yuan} \cdot \mathrm{km}^{-2} \cdot \mathrm{a}^{-1}\right)\end{array}$ \\
\hline Other land & 0.0723 \\
\hline Construction land & -0.65 \\
\hline Dry land & 4.5977 \\
\hline Forest and grassland & 10.83 \\
\hline Aquaculture & 38.89 \\
\hline Reservoirs & 1.63 \\
\hline Paddy field & 4.5977 \\
\hline Rivers & 1.63 \\
\hline Lakes & 1.63 \\
\hline
\end{tabular}


Table 4. Indicator weight of ecosystem evaluation in Ningde coastal zone.

\begin{tabular}{|c|c|c|c|}
\hline Guideline level $A$ & Weight & Indicator level $I$ & Weight \\
\hline \multirow{3}{*}{ Pressure $A_{1}$} & \multirow{3}{*}{0.340} & Population density $I_{1}$ & 0.161 \\
\hline & & Human disturbance $\mathrm{I}_{2}$ & 0.108 \\
\hline & & Land reclamation rate $\mathrm{I}_{3}$ & 0.071 \\
\hline \multirow{5}{*}{ State $\mathrm{A}_{2}$} & \multirow{5}{*}{0.472} & Normalized vegetation index $\mathrm{I}_{4}$ & 0.060 \\
\hline & & Shannon Diversity Index $\mathrm{I}_{5}$ & 0.098 \\
\hline & & Evenness index $\mathrm{I}_{6}$ & 0.065 \\
\hline & & Average patch area $\mathrm{I}_{7}$ & 0.134 \\
\hline & & Resilience indicator $\mathrm{I}_{8}$ & 0.114 \\
\hline Response $\mathrm{A}_{3}$ & 0.188 & Ecosystem services value $\mathrm{I}_{9}$ & 0.188 \\
\hline
\end{tabular}

and it is a concise, systematic analysis and evaluation method that combines qualitative and quantitative analysis. The main principle of this method is to construct an analytic hierarchy model and compare each indicator pair by pair, calculate the weight of each evaluation indicator, and conduct a consistency test to analyze and judge the evaluation target. This method has high practicability and effectiveness when dealing with relatively complex and fuzzy problems.

The weights of the evaluation indicators of the Ningde coastal ecosystem were determined by the AHP and are shown in Table 4.

\section{Comprehensive Index of Ecosystem Evaluation}

Owing to the differences in the indicator units, it is impossible to compare the indicators directly. Therefore, the extreme value normalization method was adopted to non-dimensionalize each indicator data (Eq. 10).

$$
X=\frac{X_{i}-X_{\min }}{X_{\max }-X_{\min }}
$$

...where $X$ is the value of each indicator after the normalization, $X_{\mathrm{i}}$ represents the indicator value of item $I, X_{\max }$ is the maximum value of item $I$, and $X_{\min }$ is the minimum value of item $i$.

The comprehensive index value of ecosystem evaluation was calculated using Eq. 11.

$$
S H I=\sum_{i} X \times W_{\mathrm{i}}
$$

...where $S H I$ is a comprehensive index of the ecosystem, $X$ is the normalized indicator value, and $W_{i}$ is the weight value of item $i$. The smaller the SHI value, the worse is the condition of the ecosystem. In this study, the ecosystem evaluation criterion was divided into five levels based on the Ningde coastal zone (Table 5).

Table 5. Criterion and description of the ecosystem evaluation in Ningde coastal zone.

\begin{tabular}{|c|c|c|c|}
\hline Status & $\begin{array}{c}\text { Comprehensive } \\
\text { index }\end{array}$ & Description \\
\hline Good & $>1.8$ & $\begin{array}{c}\text { The landscape structure of the ecosystem is reasonable and shows a good state. The restoration ability of } \\
\text { the ecosystem is strong. The ecosystem function is perfect and stable. It is suitable for the survival and } \\
\text { development of humans. }\end{array}$ \\
\hline Fair & $1.6-1.8$ & $\begin{array}{c}\text { The ecosystem has a relatively reasonable landscape structure with strong resilience. It is still healthy, } \\
\text { stable, and suitable for the survival and development of mankind. In this situation, the ecosystem is in a } \\
\text { state of dynamic equilibrium. }\end{array}$ \\
\hline General & $1.4-1.6$ & $\begin{array}{c}\text { The landscape structure of the ecosystem is reasonable, but its resilience is general. The status of the } \\
\text { ecosystem is close to the ecological threshold, but it is still healthy. It can perform the basic function of } \\
\text { ecosystem services. Constraints factors unfit for humans' survival exists in the ecosystem. It can maintain } \\
\text { the dynamic equilibrium state of the ecosystem. }\end{array}$ \\
\hline Poor & $1.2-1.4$ & $\begin{array}{r}\text { There are defects in the landscape structure with poor resilience in the ecosystem. The ecological } \\
\text { function of the ecosystem cannot maintain its basic needs. There exist many factors restricting human } \\
\text { survival. The dynamic balance of the ecosystem is seriously threatened. }\end{array}$ \\
\hline Worse & $<1.2$ & $\begin{array}{c}\text { The ecosystem has an extremely unreasonable landscape structure with poor resilience and serious } \\
\text { fragmentation of vegetation patches. The dynamic balance of the ecosystem has been destroyed. }\end{array}$ \\
\hline
\end{tabular}




\section{Prediction of Ecosystem Status in the Coastal Zone}

\section{Different Scenarios}

Forests and grasslands not only provide large amounts of materials and energy for humans but also have many ecological functions, such as maintaining water and soil, purifying the environment, maintaining biodiversity, degrading waste, and regulating climate. In addition, they provide social functions such as tourism, leisure, and medical care. The results shown in this paper suggest that the ecosystem services value of forest and grassland in the Ningde coastal zone is much greater than that of other land-use types. The increase in forest and grassland area is bound to increase the possibility of the healthy development of the ecosystem in the study area significantly. Additionally, the municipal government of Ningde will continue to increase the area of forest and grassland in the future based on the policy of returning farmland to forests promulgated by the central government. Furthermore, the transfer of forest and grassland mainly comes from dry land and paddy field. Therefore, the different added values of the transfer probability of these three different land-use types to forest and grassland were set as different scenarios to predict the status of the Ningde coastal zone ecosystem.

The three different scenarios were as follows:

Scenario 1: Assuming that the transition probability of dry land and paddy field to forest and grassland increases by $0 \%$.

Scenario 2: Assuming that the transition probability of dry land and paddy field to forest and grassland increases by $30 \%$, whereas the transition probability of dry land and paddy field to other land use types remains unchanged. The forest and grassland do not transfer to any other land types.

Scenario 3: Scenario 3 is similar to scenario 2 , except that the increased value of the transition probability of dry land and paddy field to forest and grassland is set as $50 \%$.

\section{Markov Model}

The Markov model is a special random process from one state to another in each time stage. The primary Markov model is a model system that the random distribution of the next state depends only on the current state, while it does not depend on the previous state. This feature of the Markov model is suitable for the study of the change of land use structure. It is necessary to clarify the initial transition probability matrix of land use type before using the Markov model. The mathematical expression of the initial transition probability matrix is as follows:

$$
P_{i j}=\left[\begin{array}{cccc}
P_{11} & P_{12} & \cdots & P_{1 n} \\
P_{21} & P_{22} & \cdots & P_{2 n} \\
\vdots & \vdots & \vdots & \vdots \\
P_{n 1} & P_{n 2} & \cdots & P_{n n}
\end{array}\right]
$$

...where $P_{i j}$ is the probability that the land type $i$ is transformed into the land type $j$ from the beginning to the end, and $n$ is the number of land-use types of the study area.

$P_{i j}$ also needs to meet the following conditions:

$0 \leq P_{i j} \leq 1 \quad(i, j=1,2, \ldots, n) ; \quad \sum_{j=1}^{n} P_{i j}=1 \quad(i=1,2, \ldots, n)$

The Markov model was obtained based on the nonfollow-up influence characteristic of the Markov process and the probability formula under Bayesian conditions.

$$
P_{(n)}=P_{(n-1)} P_{i j}
$$

...where $P_{(n)}$ is the state probability at any time, $P_{(n-1)}$ is the initial state probability, and $P_{i j}$ is the probability that the land type $i$ is transformed into the land type $j$.

The Markov model relied entirely on the initial transition probability matrix to predict the state of future events. Therefore, the initial transition probability matrix of the land-use change in the Ningde coastal zone from 2009 to 2014 was obtained using the land use classification results of the study area in 2009 and 2014 with ENVI software. Then, the area of the land use types of the Ningde coastal zone in 2024 was obtained using the initial transition probability matrix and Markov model. The prediction area of each land-use type in 2024 was brought into the PSR model for calculation. Finally, the prediction results of the ecosystem status of the Ningde coastal zone was achieved in 2024 .

\section{Results and Discussion}

\section{Area Changes of the Land Use Types in Ningde Coastal Zone}

As can be seen from Fig. 3, forest and grassland, dry land, and paddy field were the main types of land use in the coastal zone of Ningde; they accounted for $38.80 \%, 31.47 \%$, and $18.52 \%$ of the entire study area, respectively, while other land-use types accounted for only $11.20 \%$ of the entire study area based on the average area value in 2000, 2009, and 2014.

Both the area of dry land and paddy field showed a downward trend over the 14 years. They decreased by $430.87 \mathrm{~km}^{2}$ and $528.57 \mathrm{~km}^{2}$, with a decrease from $36.81 \%$ and $25.40 \%$ in 2000 to $29.93 \%$ and $16.95 \%$ in 2014, respectively. However, the area of forest and 


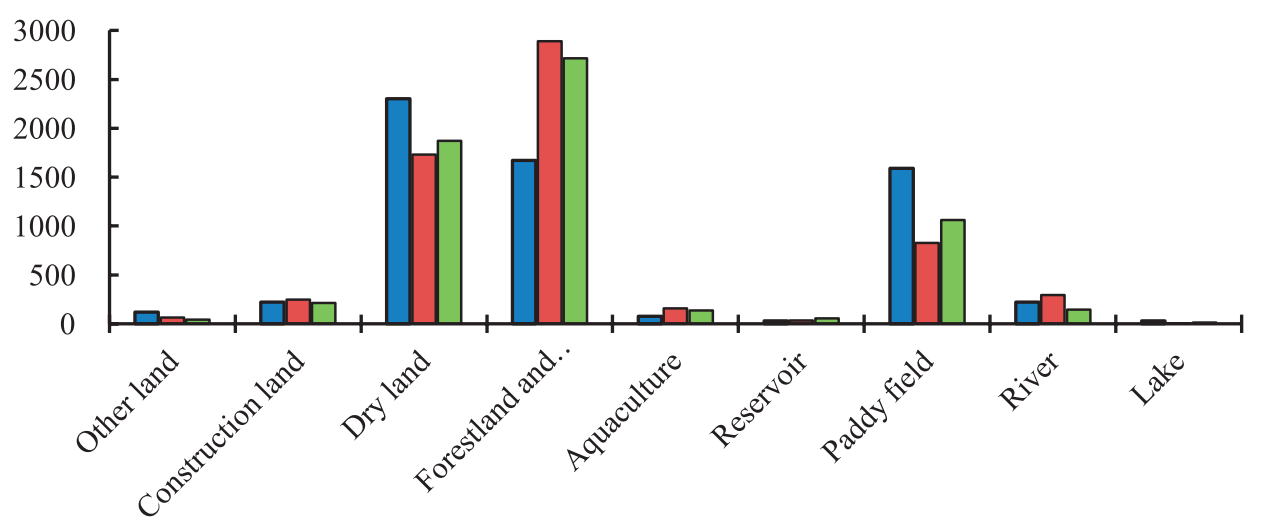

Fig. 3. Area changes of the land use types in Ningde coastal zone in 2000, 2009, and 2014.

grassland showed an upward trend from $1,669.84 \mathrm{~km}^{2}$ in 2000 to $2,717.07 \mathrm{~km}^{2}$ in 2014 . The proportion of forest and grassland in the entire study area increased from $26.7 \%$ in 2000 to $43.45 \%$ in 2014 . The aquaculture area increased from $76.24 \mathrm{~km}^{2}$ in 2000 to $137.04 \mathrm{~km}^{2}$ in 2014. The area of the reservoir increased by $29.32 \mathrm{~km}^{2}$ in 14 years, and the area of the other land, construction land, rivers, and lakes decreased during the study period.

\section{Ecosystem Evaluation of Ningde Coastal Zone}

\section{Pressure Indicator}

As shown in Table 6, the value of population density of the coastal zone of Ningde increased from 317 persons $/ \mathrm{km}^{2}$ in 2000 to 332 persons $/ \mathrm{km}^{2}$ in 2009, and then to 350 persons $/ \mathrm{km}^{2}$ in 2014. Therefore, the population density in the coastal zone of Ningde continued to increase in those 14 years. The value of the human disturbance dropped from $3.66 \%$ in 2000 to $2.57 \%$ in 2014 , which indicated that the increase in population density did not lead to an increase in human disturbance. The value of the land reclamation rate decreased from $51.99 \%$ in 2000 to $40.29 \%$ in 2014 ; i.e., the occupation of cultivated land to the land of the study area gradually decreased, and the available land resources gradually increased. The pressure of land occupation on the ecosystem gradually decreased during the study period.

As shown in Fig. 4, the value of the pressure indicator dropped rapidly from 1.624 in 2000 to 1.261 in 2009 , before rising to 1.323 in 2014. During the

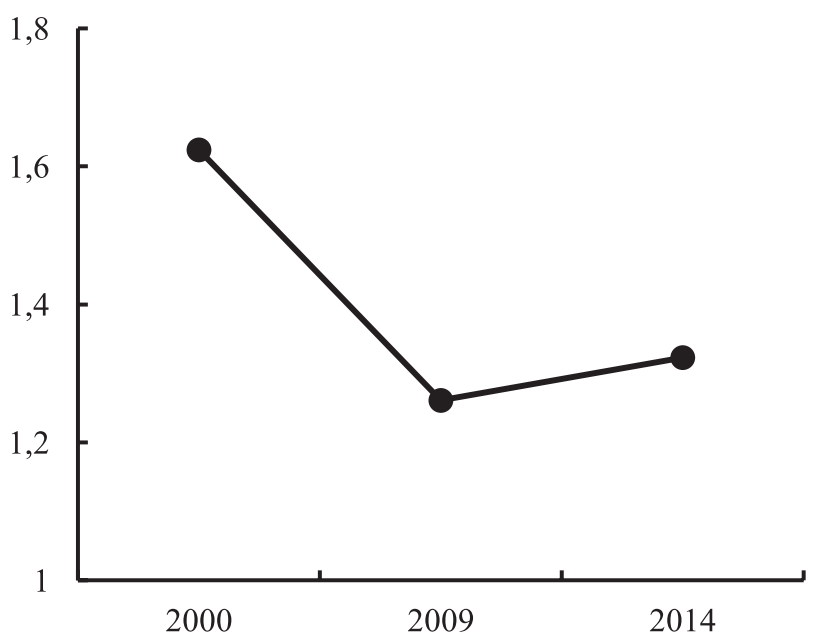

Fig. 4. Pressure indicator of Ningde coastal ecosystem.

14 years, the pressure indicator showed a significant decline first and then a slight rise. This trend indicated that the pressure on the coastal ecosystem of Ningde decreased rapidly first and then tended to remain stable during the study period.

\section{State Indicator}

Table 7 shows that the NDVI value of the Ningde coastal zone increased from 0.038 in 2000 to 0.084 in 2014. This indicated that the vegetation coverage of the Ningde coastal zone increased and the ecosystem vitality improved in the 14 years. The SHDI value of the study area dropped from 1.171 in 2000 to 1.158

Table 6. Sub-classes of pressure indicator of Ningde coastal ecosystem evaluation.

\begin{tabular}{|c|c|c|c|}
\hline Years & Population density $\left(\right.$ people $\left./ \mathrm{km}^{2}\right)$ & Human disturbance $(\%)$ & Land reclamation rate $(\%)$ \\
\hline 2000 & 317 & 3.66 & 51.99 \\
\hline 2009 & 332 & 3.15 & 38.66 \\
\hline 2014 & 350 & 2.57 & 40.29 \\
\hline
\end{tabular}




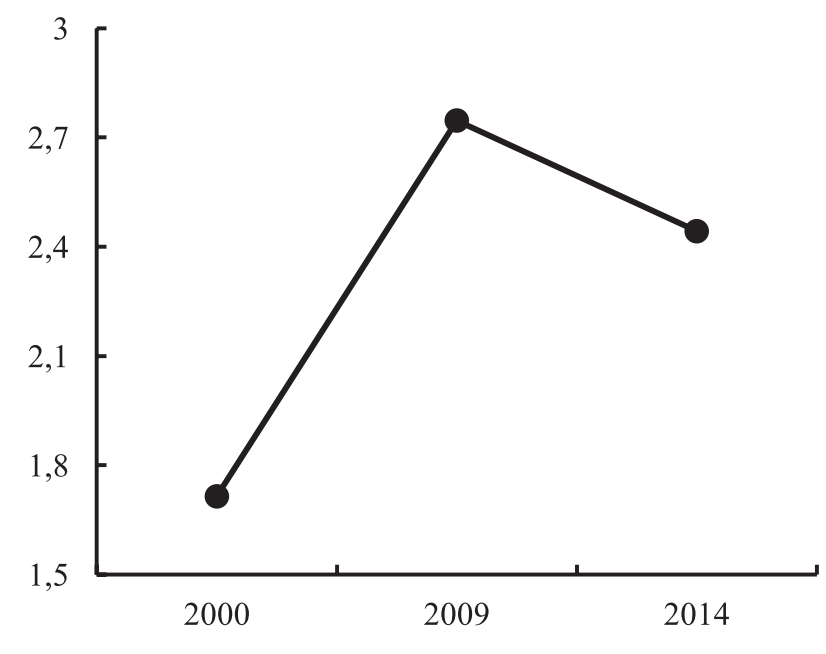

Fig. 5. State indicator of Ningde coastal ecosystem evaluation.

in 2014, indicating that the number of patch types of the Ningde coastal ecosystem showed a downward trend. The value of the evenness index of the study area dropped from 0.509 in 2000 to 0.496 in 2014, indicating that the patches in the study area tended to be unevenly distributed, and the patch dominance increased. The value of the average patch area increased from $0.453 \mathrm{~km}^{2}$ in 2000 to $0.467 \mathrm{~km}^{2}$ in 2014 , which indicated that the fragmentation of the coastal zone of Ningde gradually decreased, and the ecosystem service functions of this area gradually improved. The value of the resilience indicator of the study area continued to rise from 0.616 in 2000 to 0.660 in 2014, which indicated that the resilience of the Ningde coastal ecosystem continued to increase, and the structure and function of the ecosystem tended to be more stable.

Fig. 5 suggests that the state indicator of the Ningde coastal zone increased rapidly from 1.715 in 2000 to 2.747 in 2009 , and then decreased slightly to 2.443 in 2014. This trend indicated that the state of the Ningde coastal ecosystem improved sharply and then decreased slightly.

\section{Response Indicator}

As shown in Fig. 6, the ecosystem services of forest and grassland had the highest average value of $26277.76 \times 10^{6}$ yuan across 2000, 2009, and 2014. The three-year average value of ecosystem services of dry land, aquaculture, and paddy field was $9047.51 \times 10^{6}$ yuan, $4833.40 \times 10^{6}$ yuan, and $5324.84 \times 10^{6}$ yuan, respectively. The other land use types had a low value of ecosystem services.

From 2000 to 2014, the ecosystem services value of forest and grassland, and aquaculture showed an upward trend. Their value increased by $11341.57 \times 10^{6}$ yuan and $2364.35 \times 10^{6}$ yuan, respectively. In contrast, the value of dry land and paddy field decreased by $1981.03 \times 10^{6}$ yuan and $2430.22 \times 10^{6}$ yuan, respectively.

Fig. 7 shows that the value of the response indicator of the Ningde coastal ecosystem increased from 0.147 in 2000 to 0.645 in 2014, which showed that external disturbances did not damage the coastal ecosystem of Ningde. The ability of the Ningde coastal ecosystem to provide services to humans sharply improved and then plateaued during the study period.

\section{Comprehensive Index of Ecosystem Evaluation}

The evaluation result was obtained using the data of ecosystem evaluation indicators and Eq. 11. As shown in Fig. 8, the value of the comprehensive index of the Ningde coastal ecosystem evaluation rose rapidly from 1.389 in 2000 to 1.846 in 2009 and fell slightly to 1.724 in 2014; thus, th e status of the Ningde coastal ecosystem showed an upward trend.

The combination of the above results with those in Table 5 shows that the coastal ecosystem of the Ningde was in a poor state in 2000. By 2009, the ecosystem in this area rose to a good state and then fell to a fair state in 2014. In short, the coastal ecosystem of Ningde was in a good state after 2009. The reason is that at the beginning of the $21^{\text {st }}$ century, China joined the World Trade Organization, and China's economy entered

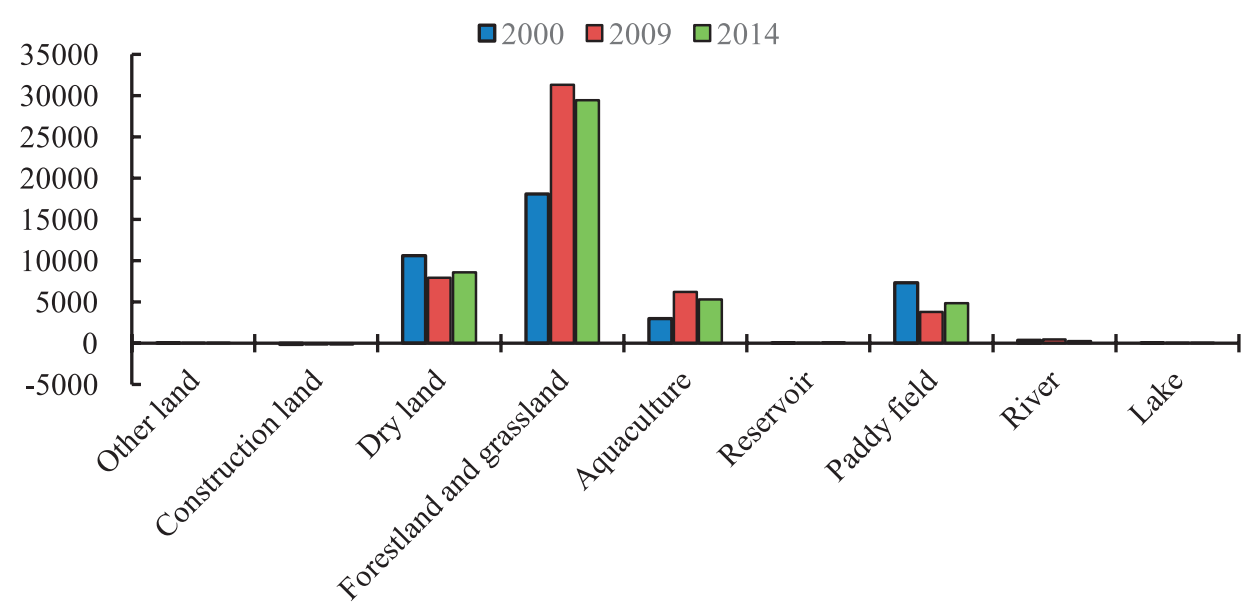

Fig. 6. Ecosystem services value of the land use types of Ningde coastal zone $\left(\times 10^{6}\right.$ yuan). 


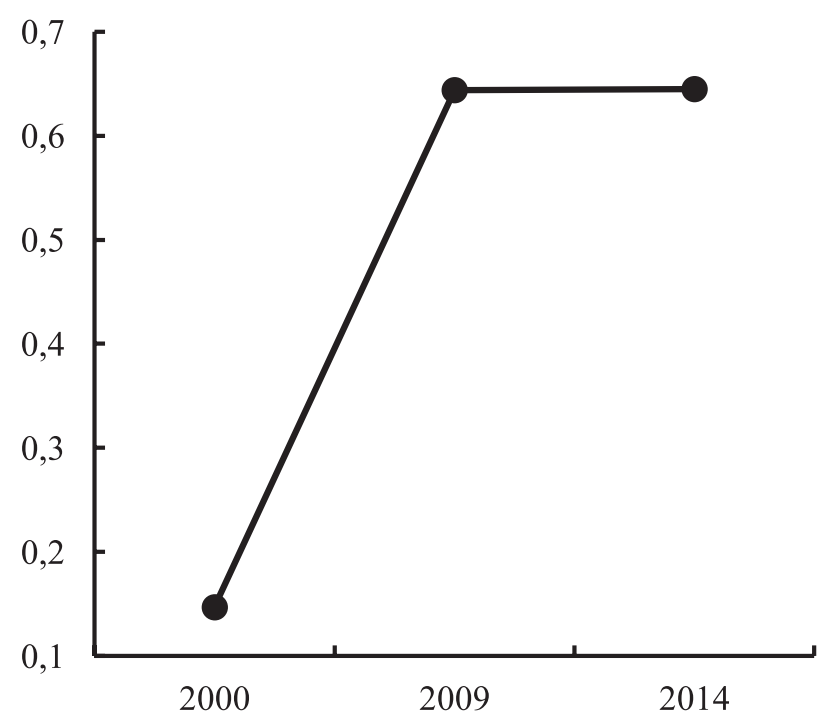

Fig. 7. Response indicator of Ningde coastal ecosystem evaluation.

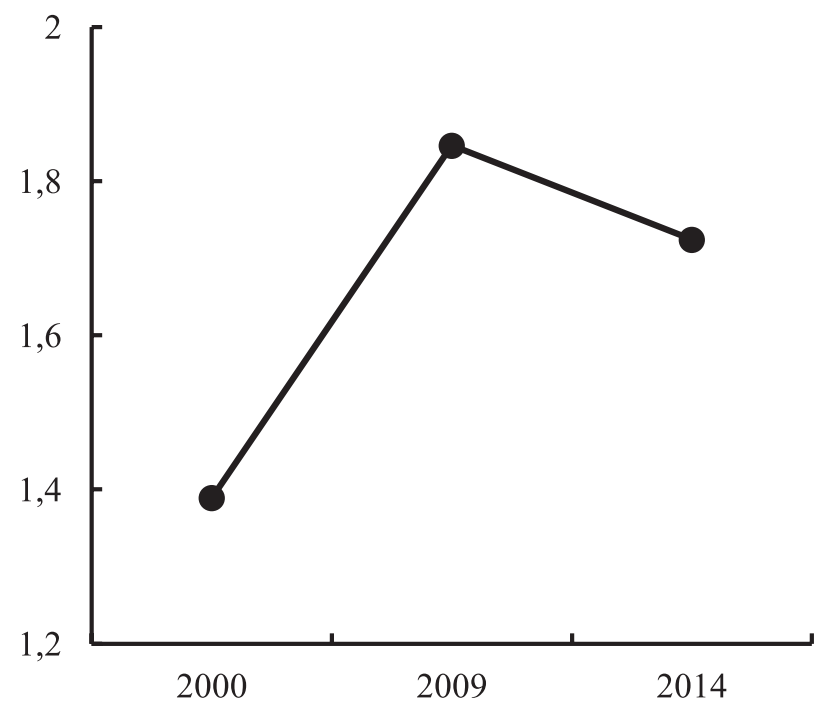

Fig. 8. Comprehensive index of the ecosystem evaluation in Ningde coastal zone.

an important stage of development. The Chinese government accelerated the pace of industrialization and urbanization to seize this opportunity of economic development and strived to enhance China's international competitiveness. The economy and urbanization of the coastal zone of Ningde developed rapidly under this background. Ningde is also one of the key production areas for commercial forests designated by the state. The purpose is to vigorously develop commercial forestry based on not destroying the ecological environment. In this context, Ningde's commercial forests continued to increase. Simultaneously, the implementation of the forest ecological benefit compensation system and the policy of returning farmland to forests have resulted in a continuous increase in forest and grassland. Therefore, the vegetation coverage of the Ningde coastal zone has increased, and the resilience of the Ningde coastal ecosystem has been enhanced. The fragmentation of the landscape structure of the ecosystem has decreased, and the value of ecosystem services of the ecosystem has increased. Overall, the ecosystem status of the Ningde coastal zone has continued to improve because of the above reasons.

\section{Prediction of Ningde Coastal Ecosystem \\ Predicted Area of Land Use Types in Different Scenarios}

Fig. 9 shows that dry land, paddy field, forest, and grassland will still be the main land-use types of the Ningde coastal zone in 2024. Forest and grassland will be the land-use types with the largest area. In scenario 1 , the area of forest and grassland is $3,183.54 \mathrm{~km}^{2}$ and it increases by $466.47 \mathrm{~km}^{2}$ compared with the area of forest and grassland in 2014. The areas of forest and grassland in scenarios 2 and 3 are $4043.25 \mathrm{~km}^{2}$ and $4113.78 \mathrm{~km}^{2}$ and they increase by $1326.18 \mathrm{~km}^{2}$ and $1396.71 \mathrm{~km}^{2}$, respectively, compared with the area of forest and grassland in 2014.

The dry land areas in scenarios 1,2 , and 3 are $1708.12 \mathrm{~km}^{2}, 1243.88 \mathrm{~km}^{2}$, and $1208.46 \mathrm{~km}^{2}$, respectively. Compared with the dry land area in 2014, they decrease by $163.09 \mathrm{~km}^{2}, 627.33 \mathrm{~km}^{2}$, and $662.75 \mathrm{~km}^{2}$, respectively.

The area of the paddy field is smaller than that of the forest and grassland and dry land in 2024. The paddy field areas of scenarios 1, 2, and 3 are $798.21 \mathrm{~km}^{2}, 525.37 \mathrm{~km}^{2}$, and $497.90 \mathrm{~km}^{2}$ and they decrease by $261.61 \mathrm{~km}^{2}, 534.45 \mathrm{~km}^{2}$, and $561.92 \mathrm{~km}^{2}$, respectively, compared with the area of the paddy field in 2014. The remaining land use types have a small area; thus, they do not significantly impact the Ningde coastal ecosystem.

Table 7. Sub-classes of the state indicator of Ningde coastal ecosystem evaluation.

\begin{tabular}{|l|c|c|c|c|c|}
\hline Years & NDVI & SHDI & Evenness & Average patch area & Resilience \\
\hline 2000 & 0.038 & 1.171 & 0.509 & 0.453 & 0.616 \\
\hline 2009 & 0.165 & 1.151 & 0.500 & 0.444 & 0.658 \\
\hline 2014 & 0.084 & 1.158 & 0.496 & 0.467 & 0.660 \\
\hline
\end{tabular}




\section{$\square$ Scenario $1 \quad \square$ Scenario $2 \quad \square$ Scenario 3}

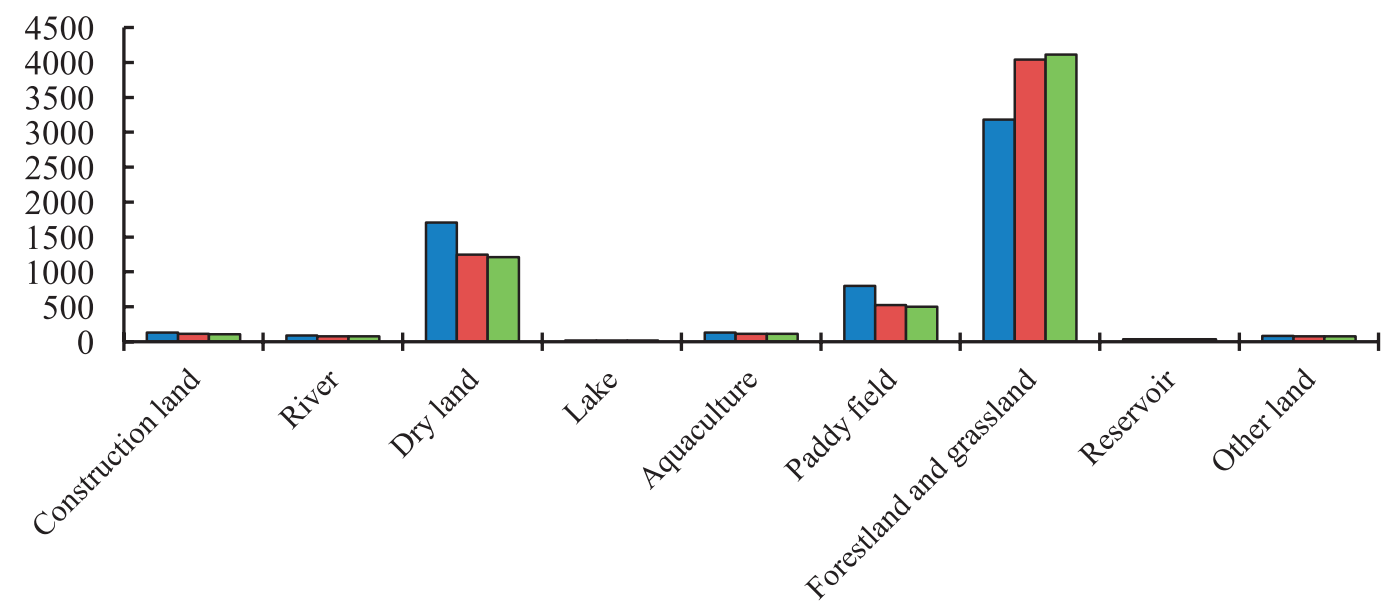

Fig. 9. Predicted area of the land use types of Ningde coastal zone in the different scenarios in $2024\left(\mathrm{~km}^{2}\right)$.

\section{Predicted Status of Ningde Coastal Ecosystem}

As shown in Table 8, the values of the pressure indicator of scenarios 1, 2, and 3 are 1.690, 1.360, and 1.323 , respectively. The increase in the area of forest and grassland and the decrease in the area of dry land and paddy field will gradually reduce the pressure on the coastal ecosystem of Ningde. The value of the state indicator increases from 1.577 in scenario 1 to 2.069 in scenario 3 , indicating that the increase in the area of forest and grassland and the decrease in the area of dry land and paddy field will improve the state of the coastal ecosystem of Ningde. However, the state indicator in scenario 3 in 2024 is lower than that in 2014. The value of the response indicator increases from 0.405 in scenario 1 to 0.640 in scenario 3 , indicating that scenarios 2 and 3 will increase the value of coastal ecosystem services in 2024.

It can also be seen from Table 8 that the value of the comprehensive index rises from 1.395 in scenario 1 to 1.517 in scenario 2 and finally increases to 1.547 in scenario 3 . The above results combined with those in Table 5 show that in 2024, the Ningde coastal ecosystem under scenario 1 will be in a poor status. The ecosystem under both scenario 2 and scenario 3 will be in general status. Therefore, the status of the Ningde coastal ecosystem in 2024 will be worse than that in 2014. Such results show that simply increasing the area of forest and grassland and decreasing the area of dry land and paddy field cannot improve the health level of the Ningde coastal ecosystem.

The current problems should be raised and resolved to improve the status level of the Ningde coastal ecosystem. The main issues affecting the Ningde coastal ecosystem were summarized based on the previous research results of our research group [28-29].

(1) The decrease in the water area and increase in aquaculture area have led to uncoordinated development of the ecosystem services in the Ningde coastal zone. The water area of the Ningde coastal zone decreased from $277.25 \mathrm{~km}^{2}$ in 2000 to $215.46 \mathrm{~km}^{2}$ in 2014 . In contrast, the area of aquaculture increased from $76.24 \mathrm{~km}^{2}$ in 2000 to $137.04 \mathrm{~km}^{2}$ in 2014 . Therefore, this study found that in the 14 years, the water area in the coastal area of Ningde has gradually decreased and partially converted into aquaculture owing to the pursuit of economic benefits and neglect of ecological and environmental protection. Finally, the material production value has improved, while hydrological regulation has decreased. These findings directly resulted in an unbalanced development of the ecosystem services of the Ningde coastal zone.

(2) The disorderly development of the aquaculture industry has destroyed the coastal ecosystem of Ningde. The Ningde coastal zone is an important production area for aquatic products in the Fujian Province. Ningde's aquaculture industry is booming, and has achieved good economic benefits. The revenue of

Table 8. Prediction of the Ningde coastal ecosystem in the different scenarios in 2024.

\begin{tabular}{|c|c|c|c|c|}
\hline & Pressure & State & Response & Comprehensive index \\
\hline Scenario 1 & 1.690 & 1.577 & 0.405 & 1.395 \\
\hline Scenario 2 & 1.360 & 1.987 & 0.623 & 1.517 \\
\hline Scenario 3 & 1.323 & 2.069 & 0.640 & 1.547 \\
\hline
\end{tabular}


aquaculture in the coastal zone of Ningde increased from 425.17 million yuan in 2000 to 1617.78 million yuan in 2014. However, owing to the lack of reasonable management and guidance, the aquaculture industry has fallen into a disorderly state, such as blindly occupying waters to expand the aquaculture area and lacking reasonable planning in layout. This has resulted in the waste of resources and the destruction of the ecological environment.

(3) The land area suitable for the forest was small in the Ningde coastal zone. The forest species in the Ningde coastal ecosystem was unitary, so it was susceptible to external disturbance. Although forest and grassland were the main land use types in the coastal zone of Ningde, the land suitable for the forest was still scarce. Based on the research of Xing [30], it can be found that only $20 \%$ of the entire forest area of the coastal zone of Ningde was highly suitable for forest.

The coastal forests have been dominated by Masson's pine and casuarina for a long time. At present, most of these tree species are close to physiological maturity. Due to the difficult regeneration of the second generation, the functions of water storage and soil conservation of these tree species were gradually reduced. In the 1970s, Spartina alterniflora was introduced from abroad to protect the tidal flats. However, it threatened the survival of mangroves that grew on the coastal zone of Ningde due to the prosperous reproduction of Spartina alterniflora.

The following countermeasures and suggestions were proposed for the above problems in the Ningde coastal zone.

(1) The aquaculture industry of the Ningde coastal zone should be reasonably planned. The management should be strengthened by law, an association for the regulation of farming industry should be established, and the supervision of practitioners should focus on strengthening. The construction of environmental regulations should be accelerated, and publicity should be increased to raise public awareness about environmental protection.

The development and utilization of land resources should have a scientific basis and should be reasonable, and the law should be followed, which is one of the necessary conditions to achieve scientific land use and promote the transformation of the regional economic development model. It will also accelerate the improvement of the protection of the ecological environment and resource development, and improve the formation of regulations and systems for energy conservation, emission reduction, and circular economy. The local government should scientifically formulate the corresponding policies and regulations to regulate the behavior of economic activities. This would give full play to the fundamental role of the market in resource allocation and establish an effective mechanism for ecological construction and protection. It would establish a comprehensive decision-making body, strengthen regional and inter-departmental cooperation, and coordinate the participation of industry and commerce, land, environmental protection, taxation, urban and rural construction, and other departments in decision-making to ensure the enforceability of regulations and policies.

Extensive and in-depth publicity and education work should be carried out, and comprehensive and in-depth popularization of the Marine Protection Law, the Sea Use Management Law, the Fisheries Law, and other relevant laws and regulations should be conducted. Publicity activities should be carried out for the protection of the marine ecological environment. Provision of full play to the role of public opinion supervision by the news media should be done to actively report and encourage the reporting of various acts that violate the ecological environmental protection law. Consciousness should be enhanced regarding the environment, and the use of environmentally friendly products should be increased; the use of public transportation or bicycles should be advocated; the construction of waste recycling and resource reuse systems should be strengthened; the public should be guided to develop habits of living and consumption that are conducive to environmental protection.

(2) Spartina alterniflora should be controlled using a combination of physical, biological, and chemical methods.

(3) The area of mangroves, known as coast guards should be expanded. Its afforestation rate should be increased, and its pest control should be strengthened.

(4) Mixed forests should be developed to enhance the stability of the forest ecosystem of the Ningde coastal zone. Schima superba and Masson's pine can be cultivated in areas with strong winds and poor soils along the coast of Ningde to exert their ability to conserve water, fix sand, and prevent wind. Castanopsis carlesii, Castanea henryi, and Aleurites montana should be planted in the Ningde coastal zone because of their ability to promote forest vegetation succession. Myrica rubra can form a fireproof forest belt, so it should be cultivated to enhance the stability of the forest ecosystem in the coastal zone of Ningde. Forest closure can enable the forest to renew itself, with appropriate human interference to improve the quality of forest stands and biodiversity. On the premise of strengthening the protection of forest resources, we should strengthen the cultivation and management of forest resources and appropriately increase the construction of ecological public welfare forests, coastal protection forests, and reforestation projects to provide a strong guarantee for the health of the regional ecosystem. We should adjust and optimize the structure of tree species and tree age composition, improve the overall productivity of forest resources, and carry out the construction project of forest protection systems in the coastal zone. The role of forests in the ecosystem should be fully utilized, and the ecological efficacy of forests should be strengthened. We will implement a phased turnover of forest stands with a single structure to improve the 
self-renewal and repair capacity of the forest ecosystem, and eventually, the forest ecosystem stability will be enhanced primarily by a compound mixed forest model.

\section{Conclusion}

The main land use types in the coastal zone of Ningde are forestland, grassland, dry land, and aquaculture. During the study period, the areas of forestland, grassland, aquaculture, and reservoirs demonstrated an increasing trend, while the areas of dry land, paddy fields, lakes, construction land, rivers, and other lands demonstrated a decreasing trend. The population density of the Ningde coastal zone gradually increased, while the human disturbance and land reclamation rate gradually decreased. The pressure indicators of the Ningde coastal zone demonstrate a decreasing trend and tend to be stable. During the study period, NDVI values and resilience indicators of the Ningde coastal zone showed an increasing trend, while the evenness index and average patch area showed a decreasing trend, indicating that the ecosystem service function of the Ningde coastal zone gradually increased and its structure gradually stabilized, and the state of the Ningde coastal zone ecosystem gradually increased.

The ecosystem service value of forestland and grassland was the highest, followed by dry land, aquaculture, and paddy fields. During the study period, the ecosystem service values of forestland, grassland, and aquaculture showed an increasing trend, while those of dry land and paddy fields showed a decreasing trend. The total ecosystem service value of the Ningde coastal zone showed an increasing trend, indicating that the ability of the Ningde coastal zone ecosystem to provide services to humans steadily increased during the study period. In conclusion, the state of the Ningde coastal zone ecosystem improved and stabilized.

In 2024, the main land use types of the Ningde coastal zone are still dry land, paddy fields, forestland, and grassland. Among them, the area occupied by forestland and grassland was the largest. Increasing the area of forestland and grassland can gradually reduce the pressure on the Ningde coastal zone ecosystem and gradually improve the ecosystem status and service value; however, the status of the Ningde coastal zone ecosystem in 2024 is poorer than that in 2014 , indicating that simply increasing the area of one land use type cannot improve the status of the whole ecosystem. Overall, improving the ecosystem status is a comprehensive and complex process.

\section{Acknowledgments}

This work was supported by the Specialized Research Fund for the Doctoral Program of Shaoyang
University (No.17ZX03), the Education Department of Hunan Province (No.19C1670). The authors wish to thank the referees for providing helpful suggestions in improving this manuscript.

\section{Conflict of Interest}

No conflict of interest exits in the submission of this manuscript, and manuscript is approved by all authors for publication.

\section{References}

1. Kilicoglu C., CETIN M., ARICAK B., SEVIK H. Integrating multicriteria decision-making analysis for a GIS-based settlement area in the district of Atakum, Samsun, Turkey. Theor Appl Climatol, 143 (1-2), 379, 2021.

2. KILICOGLU C., CETIN M., ARICAK B., SEVIK H. Site selection by using the multi-criteria technique-a case study of Bafra, Turkey. Environ Monit Assess, 192 (9), 608, 2020 https://link.springer.com/article/10.1007/s10661020-08562-1 (Accessed 31 Aug 2020).

3. RAPPORT D.J., BÖHM G., BUCKINGHAM D., CAIRNS J., COSTANZA R., KARR J.R., KRUIJF H., LEVINS R., MCMICHAEL A.J., NIELSEN N.O., WHITFORD W.G. Ecosystem health: The concept, the ISEH, and the important tasks ahead. Ecosyst Health, 5 (2), 82, 1999.

4. RAPPORT D.J., COSTANZA R., MCMICHAEL A.J. Assessing ecosystem health. Trends Ecol Evol, 13 (10), 397, 1998.

5. PANTUS F.J., DENNISON W.C. Quantifying and evaluating ecosystem health: A case study from Moreton Bay, Australia. Environ Manage, 36 (5), 757, 2005.

6. COSTANZA R. Ecosystem health and ecological engineering. Ecol Eng, 45 (8), 24, 2012.

7. CETIN M. Determination of bioclimatic comfort areas in landscape planning: a case study of Cide Coastline. Turkish Journal of Agriculture-Food Science and Technology, 4 (9), 800, 2016 [In Turkish].

8. COSTANZA R., ARGE A.R., GROOT R.D., FARBER S., GRASSO M., HANNON B., LIMBURG K., NAEEM S., ONEILL R.V., PARUELO J., RASKIN R.G., SUTTON P., VANDENBELT M. The value of the world's ecosystem services and natural capital. Ecol Econ, 25 (1), 3, 1997.

9. SEYMOUR A.C., RIDGE J.T., RODRIGUEZ A.B., NEWTON E., DALE J., JOHNSTON D.W. Deploying Fixed Wing Unoccupied Aerial Systems (UAS) for Coastal Morphology Assessment and Management. J Coastal Res, 34 (3), 704, 2018.

10. FUJITA R., LYNHAM J., MICHELI F., FEINBERG P.G., BOURILLON L., SAENZ-ARROYO A., MARKHAM A.C. Ecomarkets for conservation and sustainable development in the coastal zone. Biol Rev, 88 (2), 273, 2013.

11. CETIN M. Sustainability of urban coastal area management: a case study on Cide. J Sustain Forest, 35 (7), 527, 2016.

12. NINGDE STATISTICS BUREAU (NSB). Ningde statistical yearbook. China Statistics Press, Beijing, 2001 [In Chinese]. 
13. NINGDE STATISTICS BUREAU (NSB). Ningde statistical yearbook. China Statistics Press, Beijing, 2015 [In Chinese].

14. NINGDE STATISTICS BUREAU (NSB). Ningde statistical yearbook. China Statistics Press, Beijing, 2020 [In Chinese].

15. RAPPORT D.J. What constitutes ecosystem health. Perspect Biol Med, 33 (1), 120, 1989.

16. DU P.J., YU C., KUN T. Monitoring and analyzing wetland landscape pattern change and ecological security using remote sensing images: A case study of Jiangsu coastal wetland. Remote Sensing for Land Resources, 26 (1), 158, 2014 [In Chinese].

17. MA M.R. Study on land use/landscape changes and ecosystem health assessment of Chongming county. East China Normal University, Shanghai, 2013 [In Chinese].

18. SONG Y., MA M.G. A statistical analysis of the relationship between climatic factors and the Normalized Difference Vegetation Index in China. Int J Remote Sens, 32 (14), 3947, 2011.

19. WARRAG E.I., MALLICK J., SINGH R.K., KHAN R.A. Status of dieback of juniperus procera (African pencil cedar) in natural stands and plantation in Alsouda highlands, Saudi Arabia. Appl Ecol Env Res, 17 (2), 2325, 2019.

20. RODRIGUEZ-ECHEVERRY J., ECHEVERRIA C., OYARZUN C., MORALES L. Impact of land use change on biodiversity and ecosystem services in the Chilean temperate forests. Landscape Ecol, 33 (3), 439, 2018.

21. FANG H.Y. Impact of land use changes on catchment soil erosion and sediment yield in the northeastern China: a paneldata model application. Int J Sediment Res, 35 (5), 540, 2020.

22. LI Y.R., LI Y., FAN P.C., SUN J., LIU Y.S. Land use and landscape change driven by gully land consolidation project: A case study of a typical watershed in the Loess Plateau. J Geogr Sci, 29 (5), 719, 2019.
23. LU L.Z., ZHAN Y.Z., YE Y.M., CHEN J.Y., MU Y.M. Regional ecosystem health assessment based on land use pattern: a case of study of Zhoushan Island. Acta Ecologica Sinica, 30 (1), 245, 2010 [In Chinese].

24. ZHAO L.L., FAN X.C. Assessment of the relationship between the economy and the environment based on ecosystem services value in Nanping City, China. Appl Ecol Env Res, 16 (6), 8029, 2018.

25. SU S.C. Coastal wetland landscape pattern dynamics and its vulnerability assessment feature in Eastern of Fujian Province. Fujian Agriculture and Forestry University, Fuzhou, 2013 [In Chinese].

26. HU X.S. Spatial heterogeneity of land ecosystem service value and the coupling relationship between it and urbanization. Fujian Agriculture and Forestry University, Fuzhou, 2012 [In Chinese].

27. OU W.X. Marine ecosystem health assessment and management: a case study on the Mindong Nearshore Monitor Area. Xiamen University, Xiamen, 2006 [In Chinese].

28. HE D.J., TAN Y., LIAO X.J., WANG R., CAI J.B., YOU W.B. Selection and comparison of different methods for ecological risk assessment of heavy metals in the sediments of coastal wetlands, the east Fujian, China. Journal of Fujian College of Forestry, 34 (2), 97, 2014 [In Chinese].

29. ZHAO L.L., YOU W.B., HU H.Q., HONG W., LIAO X.J., XIAO S.H., WANG R., CAI J.B., FAN X.C., TAN $\mathrm{Y}$. Spatial distribution of heavy metals $(\mathrm{Cu}, \mathrm{Pb}, \mathrm{Zn}$, and Cd) in sediments of a coastal wetlands in eastern Fujian, China. J Forestry Res, 26 (3), 703, 2015 [In Chinese].

30. XING S.H. Evaluation on forestry land resources in Fujian based on GIS. Fujian Agriculture and Forestry University, Fuzhou, 2006 [In Chinese]. 